\title{
OS INCÊNDIOS CRIMINOSOS SOB O OLHAR DOS ESQUECIDOS NO ROMANCE PALHA DE ARROZ, DE FONTES IBIAPINA
}

\section{THE ARSONS UNDER THE VIEW OF THE FORGOTTEN IN THE NOVEL PALHA DE ARROZ, BY FONTES IBIAPINA}

\author{
Jéssica Maria Cruz Silva ${ }^{1}$ \\ Universidade Estadual do Piauí \\ Maria Suely de Oliveira Lopes ${ }^{2}$ \\ Universidade Estadual do Piauí
}

Resumo: O presente artigo analisa a obra Palha de Arroz, de Fontes Ibiapina (2004), tendo como foco a inter-relação entre ficção e história na construção de tal narrativa, que trata dos incêndios criminosos que aconteceram em bairros pobres de Teresina, capital do Piauí, durante a ditadura do Estado Novo. Escorado em autores como Costa Lima (1989), Pesavento (2006), Silva (2004), White (1994), que tratam da linha tênue entre literatura e história, bem como Lukács (2011) e Hutcheon (1991), no tocante às características do romance histórico, objetiva-se estabelecer uma reflexão crítica sobre o tema. Em linhas gerais, trata-se de um fato documentado, acrescido de outros recursos, próprios do novo romance histórico, como a ironia, a hipérbole, o grotesco, a reflexão em torno dos eventos narrados, construindo-se um texto em que história e literatura se relacionam.

Palavras-Chave: Literatura; História; Palha de Arroz; Fontes Ibiapina.

1 Endereço eletrônico: jessicaacw2016@gmail.com.

2 Endereço eletrônico: mariasuely@cchl.uespi.br. 
Abstract: This article analyzes the work Palha de Arroz, by Fontes Ibiapina (2004), focusing on the interrelations between fiction and history in the given narrative construction, which approaches the arson attacks that happened in poor neighborhoods of Teresina, Piauís capital, during the Estado Novo dictatorship. Supported by authors such as Costa Lima (1989), Pesavento (2006), Silva (2004), White (1994), who deal with the subtle line between literature and history, as well as Lukács (2011) and Hutcheon (1991), regarding historical novel characteristics, this article aims to establish a critical reflection about the theme. In general, it is a documented fact added to other resources that are new historical novel characteristics, such as the irony, the hyperbole, the grotesque, and the reflection around the narrated events, building a text in which history and literature relate to each other.

Keywords: Literature; History; Palha de Arroz; Fontes Ibiapina.

\section{CONSIDERAÇÕES INICIAIS}

Considerando a literatura como um discurso privilegiado de acesso ao imaginário de diferentes épocas, através de personagens que existem enquanto possibilidades, dotadas de credibilidade e significância, o presente artigo buscou elucidar como ficção e história se inter-relacionam no romance piauiense Palha de Arroz, de Fontes Ibiapina (2004). Tal narrativa traz o fato histórico sob o olhar da classe social marginalizada e esquecida pela memória oficial.

Nesse contexto, o leitor é colocado diante de um acontecimento documentado - os incêndios - que se passa em Teresina, durante a ditadura do Estado Novo, na Era Vargas. A intenção era espalhar o medo entre os pobres e forçá-los a se estabelecerem em lugares mais afastados, abrindo espaço para a modernização da cidade.

Como forma de viabilizar este estudo, o presente trabalho foi dividido em quatro seções. Nesta primeira, apresenta-se a hipótese da pesquisa. Na seção seguinte, imprime-se uma discussão sobre a linha tênue entre literatura e história, e como essa relação se configura na obra de Fontes Ibiapina (2004). Na terceira parte, promove-se uma reflexão sobre as condições de miséria, exclusão e abandono social, que acometiam os teresinenses que moravam em casas de 
palha, incendiadas "misteriosamente". E, na última parte, apresentam-se os resultados parciais do problema abordado.

De maneira geral, o narrador evoca um acontecimento da história oficial, conduzido por personagens que, mesmo ficcionalizadas, incorporam defeitos e virtudes do real, ao falar do absurdo da existência e das misérias humanas, denunciando a ausência de condições mínimas de dignidade social.

\section{FICÇÃO E HISTÓRIA: LINHA TÊNUE EM PALHA DE ARROZ}

Os limites entre literatura e história são sutis, uma vez que correspondem a narrativas que tomam o real como referente e se renovam em espaço e tempo, mas com um elemento permanente, o homem, que sempre se expressou através da linguagem e suas diferentes formas: oralidade, escrita, imagem, música, como explica Pesavento (2006, p. 13). Em outras palavras, ainda que a narrativa histórica tenha seus fundamentos na objetividade, e a literária centre-se na subjetividade e na imaginação, ambas têm, contudo, a apreensão do real traduzido em linguagem.

Na perspectiva de White (1994, p. 121), a distinção mais antiga entre ficção e história, na qual a ficção é concebida como a representação do imaginável e a história como a representação do verdadeiro, deve dar lugar ao reconhecimento de que só é possível conhecer o real equiparando-o ao imaginável. Isso porque as narrativas históricas não são apenas sobre os eventos, mas também sobre as relações possíveis que esses eventos suscitam: "Esses conjuntos de relações não são imanentes aos próprios eventos; existem apenas na mente do historiador que reflete sobre eles" (WHITE, 1994, p. 122). Logo, o passado (como deve ter sido) só pode ser abordado através da imaginação, o que confere ao imaginário um lugar na história. 
De acordo com Costa Lima (1989, p. 106), na história, a ficção se torna um meio auxiliar, válido enquanto provoca questões a serem testadas; na ficção, o material histórico entra na composição do texto literário para que permita a revisão de seu significado, adquirindo a possibilidade de se desdobrar em seu próprio questionamento. Dessa forma, “[...] os materiais histórico e ficcional são facilmente permutáveis, sem que cada um, ao penetrar na territorialidade do outro, mantenha a sua identidade anterior" (LIMA, 1989, p. 106).

Considerando o uso do fato histórico pela ficção, a literatura toma esses acontecimentos enquanto matéria-prima que, trabalhada artisticamente, leva o leitor a produzir e resgatar imagens no momento da leitura, encontrando uma forma de questionar os discursos instituídos como legítimos e posicionar-se historicamente, pois, “[...] hoje pensar historicamente é pensar crítica e contextualmente" (HUTCHEON, 1991, p. 121).

Esse entrecruzamento entre história e literatura se dá, essencialmente, no romance histórico, que corresponde à apropriação de fatos definidores de uma fase da história de determinada comunidade humana (BAUMGARTEN, 2000). Originalmente vinculado à produção literária do escocês Walter Scott, o romance histórico surgiu durante o século XIX, ainda na vigência do Romantismo, desempenhando importante papel na construção de identidades nacionais que almejavam se afirmar pela diferença. No sistema literário brasileiro, obras como As Minas de Prata (1862) e A Guerra dos Mascates (1873), de José de Alencar, não só apontavam para a construção de painéis culturais que atestassem a autenticidade da nova nação, como também ancoraram essa literatura na vertente do romance histórico, conforme atesta Baumgarten (2000, p. 169).

O romance histórico, tal como foi concebido em sua origem, apresenta algumas marcas que lhe são essenciais (LUKÁCS, 2011): traça painéis históricos; vale-se de personagens fictícios na descrição dos fatos; as personalidades históricas, quando presentes, são apenas citadas ou aparecem em plano de fundo; 
os fatos documentados são utilizados a fim de conferir veracidade ao texto literário; o narrador, geralmente, aparece em terceira pessoa, sugerindo a ideia de distanciamento e imparcialidade. Além disso, o romance histórico deve mostrar não apenas o que causou os acontecimentos no passado, mas também os efeitos produzidos, referenciando, ao lado de elementos literários e estéticos, componentes linguísticos, sociais, políticos e econômicos (SILVA, 2004).

Os recursos descritos acima são empregados por Fontes Ibiapina (2004), em Palha de Arroz, cujo enredo traz o seguinte fato histórico: os diversos incêndios criminosos, principalmente em casas de palha, nos subúrbios vizinhos ao centro urbano de Teresina, durante a década de 1940. Considerado como "[...] herdeiro do Romance de 30" (LIMA, 2009, p. 205), a produção ficcional de Fontes Ibiapina atrela-se ao Modernismo Regionalista, o que mostra que o escritor piauiense não esteve isolado do panorama literário nacional. Segundo Bosi (2013, p. 415), os abalos que sofreu a vida brasileira, em torno de 1930, dentre eles a crise cafeeira, a Revolução de 30, o declínio do Nordeste, a ditadura que se instalou no Brasil com Getúlio Vargas, além da Segunda Guerra Mundial, condicionaram novos estilos ficcionais, acompanhados de uma visão crítica das relações sociais, reconfigurando o regionalismo romântico a partir de uma perspectiva realista dos acontecimentos, e não idealizadora.

Romancista, contista e conhecedor das tradições e do folclore piauiense, João Nonon de Moura Fontes Ibiapina (1921-1986) tem seu conjunto de obras permeado por casos populares, trazendo aspectos do homem comum e regional. Através de uma linguagem simples, com tom coloquial e humorístico, o autor faz uso de provérbios, modismos, dizeres regionais, oralidades, clichês: “É o mundo sertanejo marcado em sua obra - os quadros naturais, sociais, linguísticos e culturais" (LIMA, 2009, p. 205).

A vasta produção literária de Fontes Ibiapina divide-se em contos, dentre os quais estão Chão de meu Deus (1958), Brocotós (1961), Pedra bruta (1964), Destinos 
de contratempos (1974), Quero, posso e mando (1976), Eleições de sempre (1985); romances, como Sambaíba (1963), que marca sua estreia como romancista, Palha de Arroz (1968), corpus deste trabalho, Tombador (1971), Nas terras do Arabutã (1984), Vida gemida em Sambambaia (1985), com o qual ganha o VII Concurso Nacional do Clube do Livro, tematizando o ciclo da seca entre 1932 a 1953, Curral de Assombrações (1985); folclore, como Paremiologia Nordestina (1975), Passarela de Marmotas (1975), Crendices, superstições e curiosidades verídicas no Piauí (1993), publicada postumamente; incluindo, ainda, crônicas, a peça teatral O casório da Pafunsa (1982), e o Dicionário de brasileirismos no Piauí, publicado, em 2002, pela Academia Piauiense de Letras, em convênio com o Banco do Nordeste, o qual reúne pesquisas do autor, contribuindo para que um linguajar tão expressivo não se perdesse por falta de registros escritos (SILVA, 2005).

Em linhas gerais, Fontes Ibiapina tem na história o ponto de partida para a maioria de suas narrativas, o que lhe dá margens para a sondagem dos fatos documentais e da realidade ficcional, produto do trabalho criativo do escritor. Segundo Silva (2005, p. 72), mesmo tratando de temas regionais, as marcas de universalidade são transportadas para suas obras, rompendo os limites geográficos do Estado. Ao abordar os desníveis sociais, o autor piauiense evoca “[...] problemas políticos, econômicos e educacionais, ficcionalizando-os de forma a transplantá-los para as páginas do livro, em linguajar simples, porém carregado de muita expressividade" (SILVA, 2005, p. 72).

Palha de Arroz é considerado o segundo romance da literatura piauiense que delineia um perfil detalhado da sociedade de Teresina. É precedido por Um manicaca, de Abdias Neves (1909), cujo enredo, marcadamente naturalista de cunho documental, registra a fisionomia social da capital do Piauí na virada do século XIX: “uma sociedade de baixa classe média, preconceituosa, provinciana e fortemente marcada pelo clero" (LIMA, 2009, p. 58). A manifestação histórica do texto de Fontes Ibiapina (2004) revela-se quando o narrador relata a história 
de um povo segregado pela ideologia dominante, que separa ricos de pobres, constituindo-se como um romance regionalista marcado pela denúncia: o mundo em guerra, o país submetido à ditadura do Estado Novo, o Piauí sem oportunidades de emprego, Teresina como cidade suja, escura e sem garantir dignidade social à maioria de seus habitantes.

Temas relacionados à capital piauiense aparecem ironizados em Palha de Arroz, como o título de cidade verde e a referência ao Conselheiro Antônio José de Saraiva, "[...] fundador da Cidade Verde em plena chapada do Corisco. Que Deus o tenha em um Bom Lugar. Verde é esperança. E a gente sofrendo até mesmo de esperar" (IBIAPINA, 2004, p. 15). Sem esquecer dos incêndios das casas de palha, mencionados pelo autor, no trecho abaixo, para ridicularizar os propósitos urbanistas em uma cidade que não os via concretizados:

O fumo subia. [...] Casas e mais casas de palha se queimando. [...] Palha de Arroz se indo. Também... pudera! Um subúrbio imundo bem no centro da cidade. Se ao menos noutra cidade qualquer! Mas, a capital? Que impressão teriam do Piauí os turistas que por ali passavam?! Que sairiam pensando de nosso povo?! De nossa terra?! De nossa cultura?! De nosso progresso?! (IBIAPINA, 2004, p. 32)

Esses incêndios teriam sido motivados pela tentativa clandestina da elite dirigente do Estado, através da polícia local, de retirar os pobres dos arredores do centro da cidade, empurrando suas habitações para a periferia, e propiciando a higienização e "modernização" da capital. Tais fatos provocaram medo generalizado e mantiveram-se, por muito tempo, silenciados, isso porque acontecimentos que possam macular a imagem do Estado são omitidos. No entanto, Pollak considera que “[...] o longo silêncio sobre o passado, longe de conduzir ao esquecimento, é a resistência que uma sociedade civil impotente opõe ao excesso de discursos oficiais" (POLLAK, 1989, p. 05).

Palha de Arroz configura-se, então, como conservador dessa realidade esquecida e marginalizada pelo discurso oficial, no qual vivem e agem 
personagens criados pelo narrador, em um mundo imaginário (diegese), mas partindo de fatos concretos: a história de um povo, em determinada época (SILVA, 2004). Dito de outra forma, Fontes Ibiapina (2004) traz outras ações secundárias, que se entrelaçam no enredo, mas tem nos acontecimentos verídicos o elemento que conduz a diegese para uma realidade exterior à narrativa. Prova disso são as referências à ditadura getuliana e à Segunda Guerra Mundial, momentos históricos esses que marcam a localização temporal do romance piauiense:

Tanta gente por aí afora falando em fim de Ditadura!... Pra quê?!... Tanta gente falando em Democracia!... De nada adiantava mudar as coleiras e serem os mesmos cachorros. [...] Quando os incêndios tiveram início, o mundo estava em guerra. Em primeiro lugar a Pátria. O mais para depois. Talvez até que agora fosse solucionado o problema dos incêndios. Por conseguinte, na opinião dos da panela, nada de culpa tinha o Chefe de Polícia, nem o Interventor, nem tão pouco o Chefe da Nação. O culpado de tudo tinha sido mesmo o conflito mundial que não dava um dedo de tempo de sobra para os homens tratarem de coisas internas. A maldita e sanguinária Alemanha responderia por tudo aquilo e outras tantas calamidades e misérias. (IBIAPINA, 2004, p. 14 e 31, grifo do autor)

Observa-se, no trecho acima, além da referência aos fatos da história oficial, a ironia em relação à ação míope das autoridades, perante a situação de miséria do povo, e o favorecimento da elite, cuja falsa moralidade é objeto de um discurso permanentemente irônico, pois "[...] o 'tipo' tem poucas funções, exceto como algo a ser atacado com ironia" (HUTCHEON, 1991, p. 151, grifo da autora).

A oposição política é representada pelo jornal O Piauí, jornal da época, fundado em 1933, ligado ao Partido Liberal (LIMA, 2009). Em Palha de Arroz, o personagem Juliano era o jornalista que escrevia para O Piauí, denunciando os incêndios criminosos e também os desmandos da polícia:

Muita gente dava na vida da Polícia, do Chefe. 'O Piauí', jornal pequeno, mas de língua de légua e meia, editado pela Oposição que já começava a se engatinhar, chegava a dizer que o homem era vil três vezes - Vil-mar, Vil-ela 
e vil na administração. Invenção na certa do Juliano, homem de cabeça doida de sabida para arrancar repente. [...] No dia seguinte, lá se vinha no jornal ‘ $\mathrm{O}$ Piauí o maior artigo que se escreveu acerca dos incêndios de Teresina - 'O Fio da Meada'. Um artigo do Juliano sobre o incêndio da Palha de Arroz. Uma bomba! (IBIAPINA, 2004, p. 29 e 33, grifos do autor)

Através desse trecho, é possível inferir que a ficção, conforme Hutcheon (1991, p. 152), costuma incorporar e assimilar os dados da história oficial, para proporcionar uma sensação de verificabilidade ao mundo ficcional. Logo, cabe à literatura o papel de dar voz aos que foram impedidos de denunciar o que ocorria naquele período, levando o leitor a inquietar-se diante de acontecimentos com valor histórico-documental.

Elementos históricos secundários também são relacionados ao fato principal, garantindo-lhe autenticidade. "Ao serem colocados no contexto histórico concreto, caracterizam o discurso histórico e, ao serem usados no discurso literário, atribuem-lhe uma expressão realista" (SILVA, 2004, p. 220). Dentre esses elementos, destaca-se a localização espacial, pois os personagens ficcionais deslocam-se em espaços precisos e reconhecidos geograficamente: Teresina e alguns de seus bairros (Palha de Arroz, Mafuá, Piçarra, Vermelha, sendo os três últimos ainda existentes), o Colégio Diocesano, até hoje uma das mais conceituadas instituições teresinenses, Timon, rio Parnaíba, Mato Grosso, Uruguaiana, entre outros locais descritos com precisão.

Esse reconhecimento geográfico produz a impressão de que as ações realmente ocorreram ali, como na citação abaixo, na qual o personagem Pau de Fumo explica a sua esposa, Conceição, para onde Negro Parente tinha viajado, em busca de melhores condições de vida:

Uruguaiana, Ceição, é extremo com a Argentina. Aliás, a maior parte do município extrema com o Uruguai, tanto que o nome vem de Uruguai e Ana (que Santa Ana é a padroeira da cidade). Mas a cidade mesmo fica defronte à Argentina. [...] Iria ver aqueles pampas, aquelas manantiais que tanto conhecia através de história e geografia. Iria conhecer Uruguaiana com a sua 
famosa Praça da Redenção, onde parte das forças do Ditador Francisco Solano López se entregara e baixara as armas na célebre Guerra do Paraguai. (IBIAPINA, 2004, p. 181-182, grifo do autor)

Outro elemento que liga o tempo histórico ao tempo ficcional é a datação cronológica. Na narrativa analisada, a data exata só aparece em duas cartas: uma escrita pelo Padre Salviano a uma moça por quem tinha interesse, mas que nem chegou a ter seu conteúdo revelado, pois Negro Parente tomou a carta do filho, Antonino, a quem o padre pediu que levasse a carta, pois não queria o rapaz visto como alcoviteiro. A mesma foi datada em "5 de junho de 1945" (IBIAPINA, 2004, p. 108). A outra carta foi escrita por Pau de Fumo, destinada ao Negro Parente, em “20 de março de 1947” (IBIAPINA, 2004, p. 183).

Entretanto, outros acontecimentos e referências feitas pelos personagens evidenciam a época centralizada no romance em estudo: a década de 1940; Segunda Guerra Mundial; ditadura do Estado Novo; governo de Leônidas de Castro Mello, no Piauí; as articulações políticas já na fase final da ditadura militar - “A Ditadura está de velas nas mãos. O Brigadeiro Eduardo Gomes vem aí mesmo. E como ele diz: a coisa vai mudar de rumo" (IBIAPINA, 2004, p. 119). E ainda, o desenlace negativo após o resultado das eleições, com a derrota de Eduardo Gomes e a vitória de Eurico Gaspar Dutra, Ministro de Guerra na Era Vargas: "Se o Brigadeiro Eduardo Gomes tivesse ganho as eleições, não estaria assim [...] Mais de dez anos sem campanha política. Passaram uma vida roubando (na Ditadura), roubaram as eleições do Brigadeiro" (IBIAPINA, 2004, p. 203).

Alguns personagens históricos também aparecem em Palha de Arroz, mas apenas integrando o plano de fundo da narrativa, quando mencionados pelos personagens da ficção, principalmente por Pau de Fumo, que faz alusão a muitas obras e autores lidos por ele, durante o tempo em que estudou no Colégio Diocesano, como no excerto abaixo: 
Li quase toda aquela biblioteca do Estado. Se eu fosse explicar pra você o que sei sobre a Origem das Espécies, com base em Darwin e Haekel, você fica até doido. Li e reli A Ética e A Política de Aristóteles [...] Também A República de Platão [...] Estudei Spinoza [...] Li Comte, Eça de Queirós, Vitor Hugo e tantos outros; [...] Só na Bíblia e no Os Lusíadas foi que não consegui penetrar com segurança. (IBIAPINA, 2004, p. 75-76, grifos do autor)

Infere-se que esses conhecidos nomes, cuja função é de referência histórica, fazem com que real e fictício se intercruzem no romance. Ao mencionar também escritores da literatura brasileira como Castro Alves, Gonçalves Dias, Da Costa e Silva, pode-se destacar a natureza intertextual da narrativa, vista como uma “[...] manifestação formal de um desejo de reduzir a distância entre o passado e o presente do leitor e também de um desejo de reescrever o passado dentro de um novo contexto" (HUTCHEON, 1991, p. 157).

Desse modo, quando Fontes Ibiapina (2004) traz os populares versos de Gonçalves Dias: “Minha terra tem palmeiras, / Onde canta o sabiá” (IBIAPINA, 2004, p. 179), ele relembra as abundantes palmeiras de coco babaçu que haviam no Piauí e no Maranhão, mas que deixaram muitos em sofrimento ao perderem suas moradias, feitas dessas palmeiras, e até a vida, por conta dos incêndios. Foi o que aconteceu com Zefinha, filha do personagem Pau de Fumo, asfixiada pelo fogo que consumiu sua casa no bairro Palha de Arroz:

Coco babaçu... Ociosa fonte econômica dormindo em parte do Piauí e em todo o Maranhão imenso. É mesmo. ‘O Brasil é rico mas não sabe o quanto possui'. Que tal! O próprio governo confessando a negligência nacional. Aquelas palhas eram da casa em que ela nascera e vivera até o infeliz dia do incêndio da Palha de Arroz. Palhas que também cobriram qualquer coisa de felicidade duma mulher pobre, enquanto os homens quiseram que ela fosse qualquer coisa de feliz no mundo. Palha de coco babaçu. - Minha terra tem palmeiras, Onde canta o sabiá. (IBIAPINA, 2004, p. 178-179, grifo do autor)

Percebe-se que a intertextualidade se dá, no trecho acima, através da ressignificação dos versos de Gonçalves Dias, dentro de um novo contexto, e 
também pela ironia que Fontes Ibiapina (2004) conota ao associar a beleza das palmeiras da Canção do exílio ao sofrimento de um povo, que não usufruía das riquezas do país: “Mas Zefinha era original. O único naqueles trajes - uma mortalha de cinza e asas e grinalda de palha de coco" (IBIAPINA, 2004, p. 178).

A ficção assume, portanto, uma consciência política e social, revelando a realidade piauiense, especificamente, em Teresina, dando enfoque ao mundo suburbano, com seus desempregados, prostitutas, malandros, marginalizados por um sistema de divisão de classes. Em outras palavras, a literatura apresentase como uma forma de representação do mundo, trazendo consigo sentimentos, desejos e anseios de um povo que vivenciou determinada época.

\section{O FATO HISTÓRICO SOB O OLHAR DOS ESQUECIDOS}

Entre 1937 e 1945, período denominado pela historiografia brasileira de Estado Novo, Teresina recebeu algumas intervenções valorizadas pelo discurso oficial: tratamento urbano, novas áreas de sociabilidade, adequação das ruas para a circulação do automóvel, objeto de consumo de poucos. Tudo isso visava transformá-la em uma cidade moderna, como afirma Nascimento (2011, p. 04).

A transferência da capital do Piauí de Oeiras para Teresina, sendo esta a primeira capital planejada do país, inaugurada em 1852, tinha um objetivo idealizador básico:

[...] a cidade sonhada por Antônio Saraiva deveria se transformar em centro dinâmico da economia e sociedade piauienses. Foi pensada para alavancar o progresso no Piauí e sua posição do ponto de vista geopolítico indicava-a como o motor do desenvolvimento da Província. Tenha a cidade, nascida na 'Chapada do Corisco', alcançado o seu desiderato ou não, foi desejada. (NASCIMENTO, 2006, p. 199, grifo do autor)

No entanto, existia outra parte da cidade, onde a maioria morava em casas de palha, as ruas não eram calçadas, não havia luz elétrica: “Noite escura. A 
cidade também era uma escrava. Escrava do governo. A Usina morta. Já ia pra muito tempo com a capital sem luz elétrica" (IBIAPINA, 2004, p. 52), tampouco água tratada e canalizada, e os moradores eram atingidos por doenças, como febre tifoide, varíola, tuberculose. Em Palha de Arroz, o enfoque está nesse segmento social, representado por personagens que não se beneficiavam das transformações urbanas, como mostra o trecho abaixo, no qual Pau de Fumo lamenta a condição de vida miserável de sua família:

Os meninos nus e descalços e doentes. Ceição já parecendo estar tuberculosa, magra de dar dó. Fininha!... que nem vara de virar tripa ou cipó de dar em alma. [...] Teresina estava cheia até a tampa de tuberculosos, e sem um pequeno sanatório para remédio. Miséria! Parecia lenda a construção do Pavilhão. Obra do governo da União. [...] Verbas e mais verbas chegando e os ladrões oficiais metendo-as nos bolsos. Papando tudo. E a construção parada que nem água de poço. Servindo de amparo, às caladas da noite, para os malandros exploradores de mocinhas pobres. Antro de prostituição em pleno coração da cidade. (IBIAPINA, 2004, p. 203)

Percebe-se que o romance piauiense traça percursos sinuosos que cruzam eixos temáticos ligados ao crime, à prostituição e aos incêndios, expondo as mazelas de um espaço condicionado à promiscuidade, com enredos, falas e personagens marcados pelo sofrimento:

Bem sei o que pobre sofre, especialmente pobre da Palha de Arroz, Barrinha, Curral-das-Éguas, Cai-n'Água, Balança-Cu, Quatorze Bandas [...] Havia mulheres sem marido às carradas naqueles dois bairros, - Palha de Arroz e Barrinha. Dois bairros irmanados, gêmeos e de iguais destinos. Iguais tanto em sofrimentos como pobreza e semodagens e demais desgraças do mundo, especialmente doenças. (IBIAPINA, 2004, p. 47 e 101)

O estereótipo da pobreza é, portanto, construído através da estética da denúncia social, permeada por expressões regionais de desespero daqueles que tinham suas casas incendiadas ou que imergiam na criminalidade, ficando à mercê da violência policial. Nessas condições, muitos eram impelidos ao crime como tentativa de sobrevivência. É o que acontece com o personagem Chico da 
Benta, vulgo Pau de Fumo: "Se não encontrava serviço... Nem tinha dinheiro em baú [...]. E se não era empregado do governo, como roubar de outra maneira?! Como sustentar Genoveva e três filhos?" (IBIAPINA, 2004, p. 14).

Observa-se que o crime se configura como um dos elementos caracterizadores do cotidiano dos pobres, no subúrbio teresinense, fazendo parte do programa de vida desse grupo social, do qual fazia parte Pau de Fumo, “[...] o gatuno mais salafra da Palha de Arroz" (IBIAPINA, 2004, p. 12). Com os pais mortos e não tendo condições de concluir os estudos, o personagem tenta obter emprego, porém, apesar de ter sido aprovado em três concursos públicos, nunca foi nomeado. Para não morrer de fome junto com a família, adentra o mundo da criminalidade.

Quando encontra uma chapa de carregador perdida na rua, Pau de Fumo reassume a identidade de Chico da Benta, seu antigo apelido, pois agora teria um emprego: levar bagagens de viajantes em troca de dinheiro, e não precisaria mais viver fugindo da polícia.

Agora, porém, ia fazer questão de ser tratado pelo nome. Pau de Fumo era apenas e tão somente o ladrão. Agora seria o carregador, o homem trabalhador e honesto, o pai de família que voltava ao nome de origem: Chico da Benta. [...] Pau de Fumo morreu! [...] Carregador 208! Pronto, patrão! (IBIAPINA, 2004, p. 115-116)

Apesar de esforçar-se em ter uma vida honesta, sua situação financeira continua a se agravar, e novamente ocorre a morte simbólica de Chico da Benta, com Pau de Fumo voltando a agir, na tentativa de driblar as intempéries sociais. Vale ressaltar que o referido personagem tinha consciência de sua identidade dual, ou seja, dos dois seres que habitavam seu âmago, revelados ou escondidos conforme exigia a ocasião. Logo, a denominação Pau de Fumo é dada quando o personagem, sem perspectiva de desenvolvimento financeiro, é levado a 
procurar como meio de sustento a prática de furtos. Quando passa a se autodeclarar Chico da Benta, volta-se às práticas de honra e honestidade.

Após muitas situações embaraçosas, acaba sendo expulso de Teresina, sob pena de morte, caso desobedecesse à ordem da polícia. Entretanto, quando ia escoltado até o Maranhão, sob a ponte metálica que liga Teresina a Timon, Pau de Fumo conclui que, “[...] se era de um sapo viver chorando de fome e ouvindo a sapa velha e seus sapinhos chorando de fome a vida toda, melhor morrer. E o melhor lugar era aquele" (IBIAPINA, 2004, p. 213). E, assim, comete suicídio: atirando-se às águas do Parnaíba.

Outro personagem que passa por precária situação é o Negro Parente, que era "pescador de defuntos", mas, como forma de compensar os períodos escassos de resgate de corpos afogados no rio, torna-se assassino de aluguel. Após muitos fracassos pessoais e profissionais, é encorajado pela necessidade de sair do Piauí e viajar para outros estados do país (Mato Grosso e Rio Grande do Sul) à procura de condições de sobrevivência mais favoráveis.

Dessa forma, tempo e espaço de uma Teresina do século XX são colocados como elementos centrais de uma narrativa que articula fatos e personagens extraídos da realidade e aqueles exclusivos da ficcionalidade, mas que vivem episódios construídos a partir de relatos históricos e existem enquanto possibilidades. Ou seja:

Foram reais na 'verdade do simbólico' que expressam não no acontecer da vida. São dotados de realidade, porque encarnam defeitos e virtudes dos humanos, porque nos falam do absurdo da existência, das misérias e das conquistas gratificantes da vida, porque falam das coisas para além da moral e das normas, para além do confessável. (PESAVENTO, 2006, p. 15, grifo da autora)

Nessa perspectiva, o historiador que se volta para a literatura prioriza na leitura e estudo do texto não o seu valor documental, mas o seu valor de problema, visto que o texto literário oferece ao pesquisador possibilidades de 
"mostrar" ao leitor determinados fatos. Uma maneira encontrada por Fontes Ibiapina (2004) para sublinhar que Palha de Arroz não era apenas um romance para entretenimento, mas também um ato de denúncia social e política, foi referenciar a si mesmo, através do personagem Jônatas Nonato de Moraes Farias Itabaiana, ou somente Farias Itabaiana, como assegura o excerto abaixo:

Um estudante me disse que vai escrever um romance sobre os incêndios e o nosso Bairro, onde eu, você, Veva, Ceição e Antonino seremos personagens centrais. [...] Ele mesmo não diz, mas todo mundo aqui sabe que é o primeiro aluno do Liceu velho. Temos feito muitas e bonitas farras. Chama-se Jônatas Nonato de Moraes Farias Itabaiana. Mas ele, que escreve em jornais, só assina mesmo Farias Itabaiana. (IBIAPINA, 2004, p. 187)

Aos olhos do leitor atento não passa despercebido o fato que as iniciais do nome desse personagem, intencionalmente, coincidem com as do autor João Nonon de Moura Fontes Ibiapina, o que mostra mais uma vez a aproximação entre realidade e ficção no romance em estudo. Através de uma arte que grita a favor dos excluídos, percebe-se também a apologia que o autor piauiense faz à obra de Castro Alves e sua escrita de contestação à escravatura brasileira, o que se comprova pela junção de versos de Castro Alves, nas duas primeiras linhas do trecho abaixo, a outros versos ficcionais:

'Dorme cidade maldita,

Teu sono de escravidão'.

Sonha com o pobre que grita:

Senhor meu Deus! Dai-me pão!

Os dois primeiros são de Castro Alves. Os dois últimos são dele. Que tal?! (IBIAPINA, 2004, p. 188, grifo do autor)

Esses versos aparecem tanto na epígrafe de Palha de Arroz como na carta que Francisco Clemente Puciúnculo (vulgo Pau de Fumo) remete ao Negro Parente, que estava em Mato Grosso, na parte da carta que fala sobre o estudante Farias Itabaiana e sua atuação na pesquisa para escrever um romance 
futuramente, sendo os dois últimos versos de sua autoria: "Pode ser que venha mesmo o romance. Da moita que se espera é que sai o coelho, e a galinha que se espanta é que põe o ovo" (IBIAPINA, 2004, p. 188).

Diante do exposto, percebe-se que Palha de Arroz recria, através da escrita literária, fatos que emergem da história de um povo, particularmente, das classes menos favorecidas. Portanto, a verdade da ficção literária não está em revelar a existência real de personagens e fatos, mas fazer com que o historiador resgate a verossimilhança daquilo que se passou, na reconfiguração de um tempo histórico reconstruído pela narrativa, face à impossibilidade de repetir a experiência do vivido.

\section{CONSIDERAÇÕES FINAIS}

No romance piauiense Palha de Arroz, de Fontes Ibiapina (2004), há uma profícua relação entre elementos fictícios e históricos. A maioria dos personagens deriva da imaginação do autor, entretanto revelam tipos sociais que verdadeiramente existiram naquele contexto sociocultural: a sociedade teresinense, no século $X X$, principalmente as classes marginalizadas, que viviam às margens das melhorias urbanas.

Ao estudar a linha tênue entre história e literatura, que percorre a obra em estudo, percebeu-se que os incêndios criminosos em Teresina, no período ditatorial da década de 1940, foi o fato histórico que conduziu as demais ações da narrativa, mesclado aos elementos próprios do romance histórico, como a ironia, a hipérbole, o grotesco, a reflexão crítica em torno dos eventos narrados. Isto posto, o escritor de textos literários não tem compromisso com a veracidade dos acontecimentos, entretanto estes precisam ser convincentes e bem articulados, dando impressão de verdade. 
Palha de Arroz reveste-se, portanto, de um caráter desmascarador, revelando as mazelas da história social e política piauiense, sobretudo na sua truculência e instabilidade, através do olhar daqueles esquecidos pelo discurso oficial.

\section{REFERÊNCIAS}

BAUMGARTEN, Carlos Alexandre. O novo romance histórico brasileiro. Via Atlântica. São Paulo, n. 4, p. 168-177, Jul./Dez. 2000. Disponível em: [https://www.revistas.usp.br/viaatlantica/article/view/49611/53696]. Acesso em: 25/01/2021.

BOSI, Alfredo. Tendências contemporâneas. In: BOSI, A. História concisa da literatura brasileira. São Paulo: Cultrix, 2013. p. 409-532.

HUTCHEON, Linda. Poética do pós-modernismo: história, teoria, ficção. Tradução por Ricardo Cruz. Rio de Janeiro: Imago Ed., 1991.

IBIAPINA, Fontes. Palha de Arroz. 4. ed. Teresina: Oficina da Palavra, 2004.

LIMA, Luiz Costa. Narrativa e ficção. In: LIMA, L. C. A aguarrás do tempo: estudos sobre a narrativa. Rio de Janeiro: Rocco, 1989. p. 68-121.

LIMA, Luiz Romero. Fontes Ibiapina. In: LIMA, L. R. Presença da Literatura Piauiense. 9. ed. Teresina: Fundação Quixote, 2009. p. 205-212.

LUKÁCS, György. O romance histórico. Tradução por Rubens Enderle. São Paulo: Boitempo, 2011.

NASCIMENTO, Francisco Alcides do. Cidade e memória: cidades invisíveis. Outros tempos. Maranhão, v. 3, n. 3, p. 197-209, Jan./Jun. 2006. Disponível em: [https://www.outrostempos.uema.br/index.php/outros_tempos_uema/article/view/403] .=Acesso em: 09/02/2021.

NASCIMENTO, Francisco Alcides do. Teresina, a capital que nasceu sob o signo do moderno e da pobreza. In: Simpósio Nacional de História, 26., 2011, São Paulo. Anais... São Paulo: ANPUH, 2011, p. 01-15. Disponível em: [http://www.snh2011.anpuh.org/resources/anais/14/1300477414_ARQUIVO_Teresinam odernaanpuh2011.pdf]. Acesso em: 28/01/ 2021.

PESAVENTO, Sandra Jatahy. História e literatura: uma velha-nova história. In: COSTA, Cléria Botelho da; MACHADO, Maria Clara Tomaz (Orgs.). História e Literatura: identidades e fronteiras. Uberlândia: EDUF, 2006. p. 11-28.

POLLAK, Michael. Memória, Esquecimento, Silêncio. Estudos Históricos. Rio de Janeiro, v. 2, n. 3, p. 3-15, Jan./Jun. 1989. Disponível em: 
[http://www.uel.br/cch/cdph/arqtxt/Memoria_esquecimento_silencio.pdf]. Acesso em: 11/02/2021.

SILVA, Raimunda Celestina Mendes da. A representação da seca na narrativa piauiense: séculos XIX e XX. Rio de Janeiro: Caetés, 2005.

SILVA, Raimunda Celestina Mendes da. História e Ficção em Palha de Arroz. In: IBIAPINA, Fontes. Palha de Arroz. 4. ed. Teresina: Oficina da Palavra, 2004. p. 215-224.

WHITE, Hayden. Trópicos do discurso: Ensaios sobre a Crítica da Cultura. Tradução por Alípio Correia de Franca Neto. São Paulo: Editora da Universidade de São Paulo, 1994.

Nota do editor:

Artigo submetido para avaliação em: 20 de março de 2021.

Aprovado em sistema duplo cego em: 10 de agosto de 2021. 